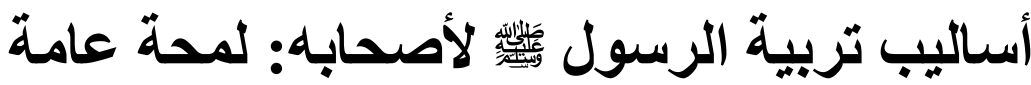

\section{Teaching Method of Prophet (SAAS) to His Followers: An Overview}

\section{Sayed Mohammad Jalal Uddin Al-Azhari*}

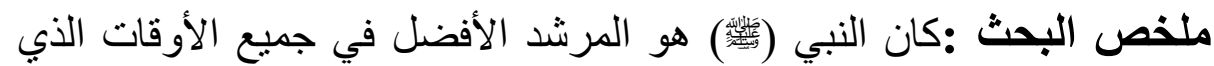

$$
\begin{aligned}
& \text { كان يعرف كيف يخاطب القلوب وجعلهم يفكرون، لذا فقد حقق تغييرًا دائميًا في الئ } \\
& \text { سلوكهم من خلال أفضل الطرق التعليمية. ورسم بعض معالم عظمة الرسول }
\end{aligned}
$$

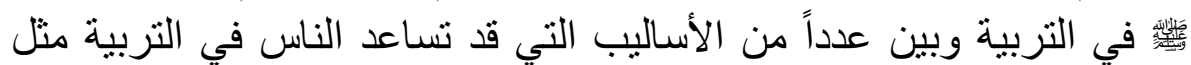

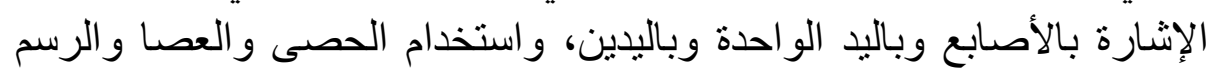

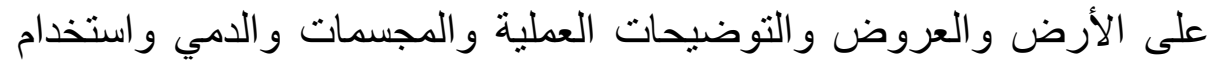

$$
\begin{aligned}
& \text { الأشياء الحقيقية وغيرها. التعرف على أهم الأساليب التربوية التي يقوم عليها } \\
& \text { منهج الرسول صلى الله عليه وسلم التربوي من خلال السنة النبوية الثريفة. } \\
& \text { الكثف عن المبادئ التربوية المستمدة من سيرته العطرة. توضيح الأساليب }
\end{aligned}
$$

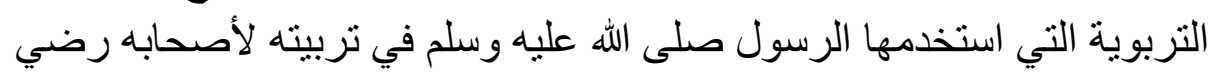

$$
\begin{aligned}
& \text { الله عنهم من خلال حياته الحافلة بالتربية. تقديم تصور مقترح للاستفادة من }
\end{aligned}
$$

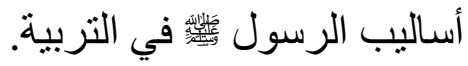

$$
\begin{aligned}
& \text { الكلمات المفتاحية: التربية، الإشارة، الاستخدام، الرسم، العروض، التوضيح } \\
& \text { العملي }
\end{aligned}
$$

Abstract: The Prophet (SAAS) was the best guide at all times who knew how to address the hearts and make them think, so he has made a permanent change in their behavior through the best educational methods. The aim and objective of the present research is to draw some salient features of Hadrat Muhammad, the Prophet of Allah (SAAS) in imparting education and good manners to his followers as well as presenting of some aspects of his methodology of gesture and posture to help sure and clear understanding, such as pointing fingers, beckoning with one or both hands, alluding with gravel and stick, drawing sign on the ground, displaying figures, hinting with dolls and various other things. Point out certain important methodology of

* Sayed Mohammad Jalal Uddin Al-Azhari, Assistant Professor, Dept. of Islamic Studies, Southern University Bangladesh, Chittagong. E-mail: jalal_cairo@yahoo.com 
teaching wisdom and training good manners by means of his own behavior, the Prophetic Sunnah. Discourse on educational principles derived from his fragrant lifestyle. Clarifying the educational methods used by the Prophet (SAAS) in his upbringing to his companions, may Allah be pleased with them, through his own lesson and conduct. Presenting a proposed scenario to benefit from the methods of the Prophet (SAAS) in education.

Keywords: Education, Signal, Draw, Deals and Practical illustration

\section{مقدمة البحث}

الحمد لله الذي بعث في الأميين رسو لا منهم, يتلو عليهم آياته ويزكيهم ويعلمهم الكتاب و الحكمة و إن كانو إنا

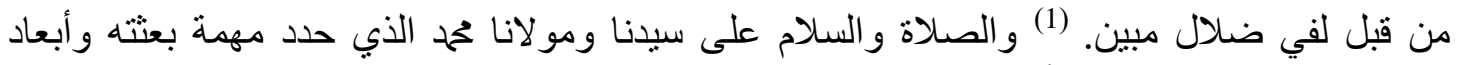

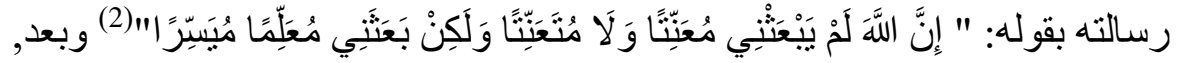

فإنه كانت مهمة البعث الإلهي في الأمة الأمية تلاوة آيات الله والتعليم بالمشافهة وحفظ الآيات والإفادة

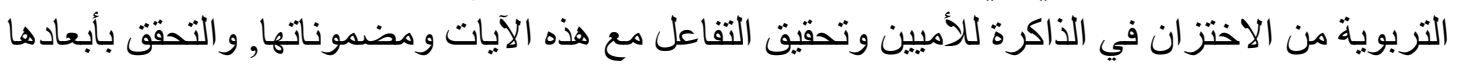

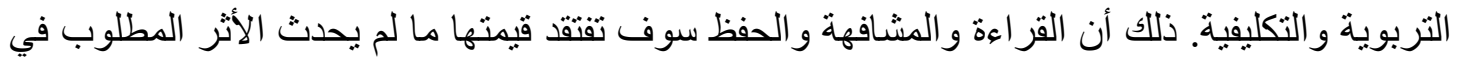

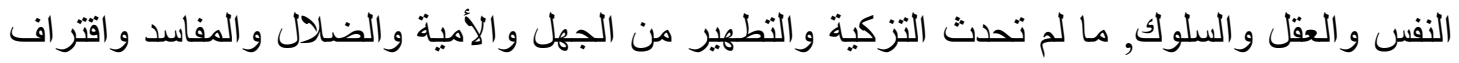
الخبائث, و التحول العملي صوب الطيبات... فالتزكية عملية تربوية تثمل العقل و النفس و السلوك.

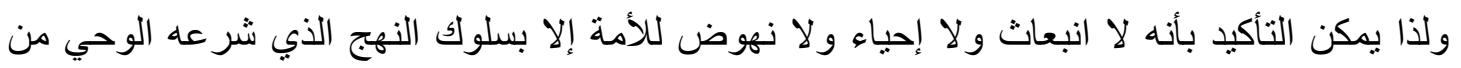
تلاوة الآيات, وتعلم القراءة والكتابة, لتحقيق التزكية النفسية والخلقية وبناء الحكمة العقلية التي يورثها لألها

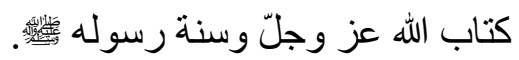

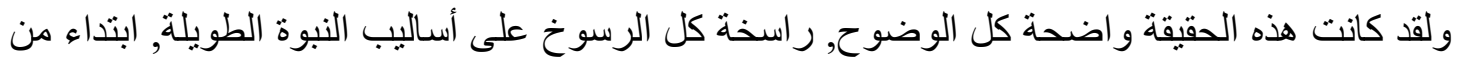

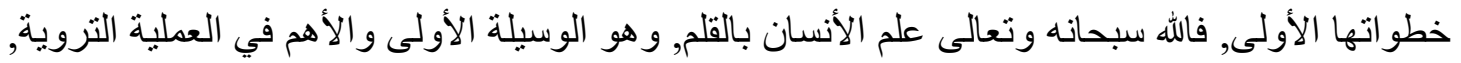

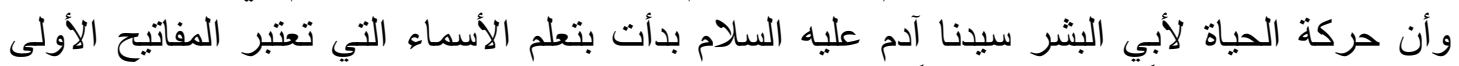

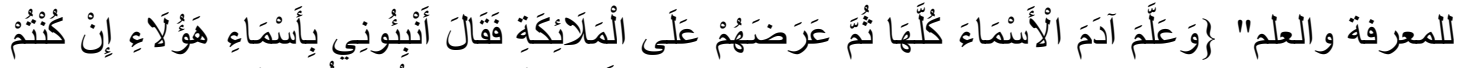

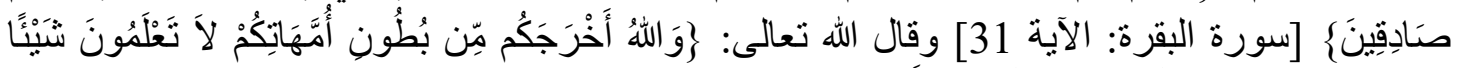

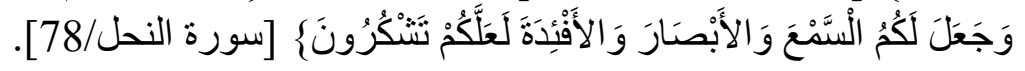

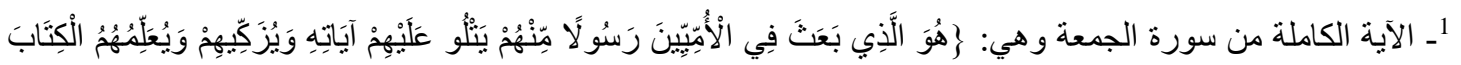

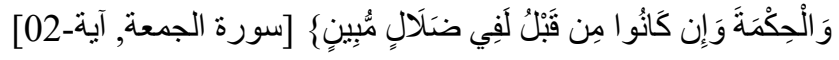

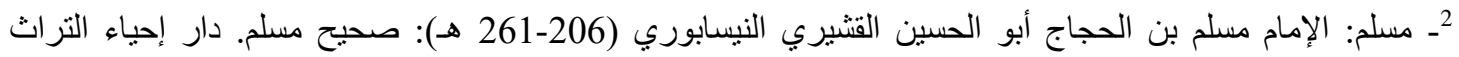

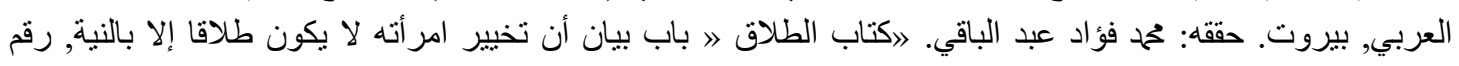
الحديث: 1478. (148. 
فالحواس هي مصادر المعرفة أو نو افذ المعرفة على العالم الخارجي, التي تمكن الإنسان من الاكتّاب

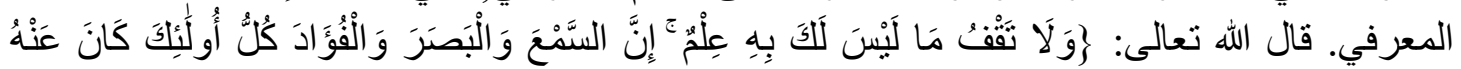

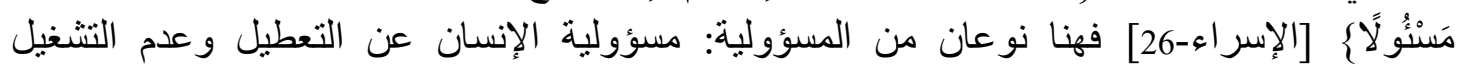

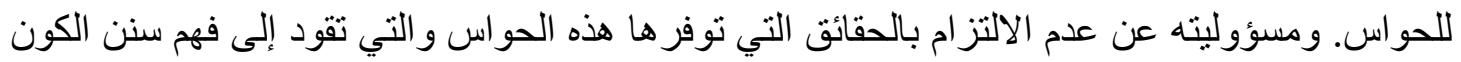
وقو انينه, و امتلاك القدرة على تسخير ها. ومن ثم الإيمان باليقين الأكبر بخالق الكون. الكون.

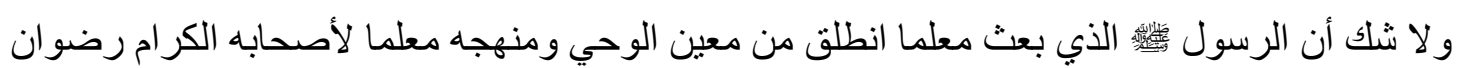

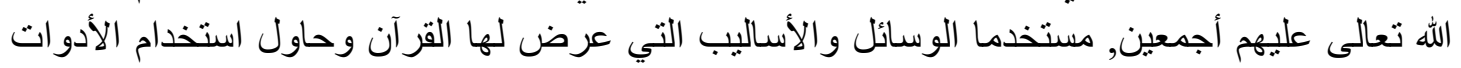
و الوسائل المتاحة في البيئة وتوظيفها لصالح تعميق المعاني والمعارف واستخدم أيضا أخبار الأمم الهم

\section{أهداف البحث}

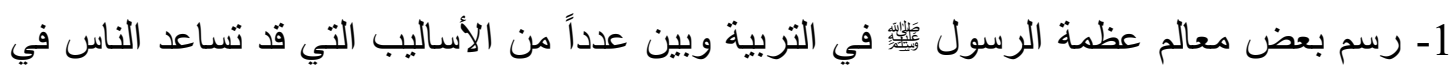

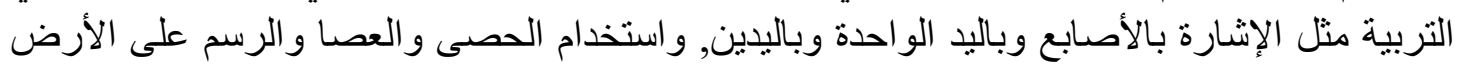

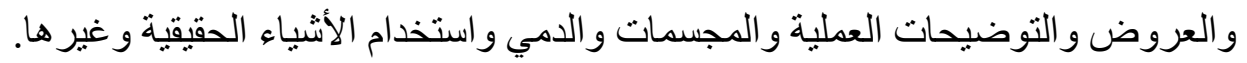

2- التعرف على أهم الأساليب التربوية التي يقوم عليها منهج الرسول التربي التربوي من خلال التراث الإسلامي . - المعرف

3- الكثف عن المبادئ التربوية المستمدة من سيرة الرسول

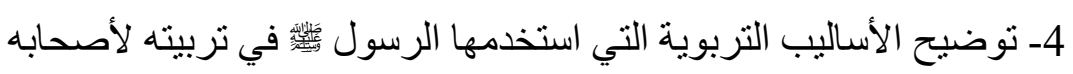
5ـ تقديم تصور مقترح للاستفادة من منهج الرسول في لتس في التربية في مؤسساتتا التربوية.

أهمية البحث

يكتسب البحث أهميته من خلال ما يلي:

1- يكثف عن الأهمية الكبرى للتربية باعتبار ها عنصر اً أساساً في بناء شخصية الفرد.

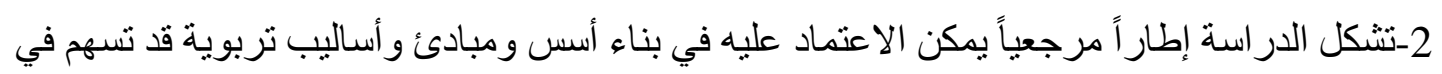

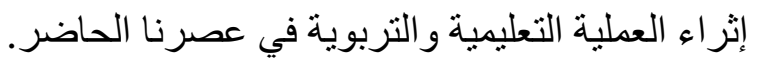
3-يمكن أن يستفيد من نتائج هذا البحث: ـ القائمون على تصميم المناهج التعليمية في بلاد المسلمين. ـ المربون آباء ومعلمين. - درجال الدعوة والإصلاح. 4-وضع صيغة مقترحة للاستفادة من منهج الرسول التربوي في مؤسساتنا التربوية. 
استخدم البحث أسلوب تحليل المحتوى من الناحية الكيفية، كأحد تقنيات المنهج الوصفي، بالوقوف على النى

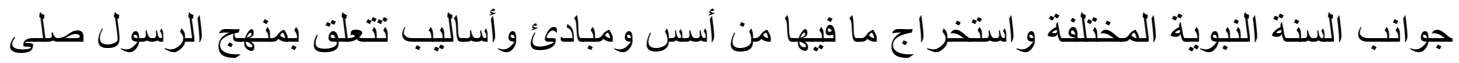
الله عليه وسلم في التربية.

\section{مفهوم التربية}

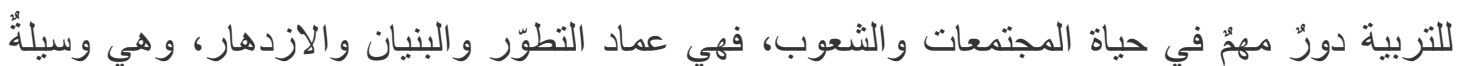

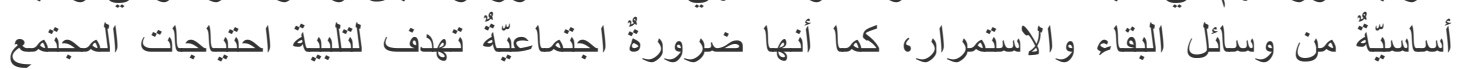

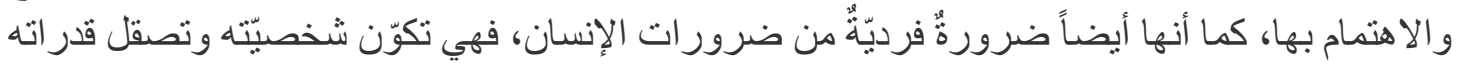

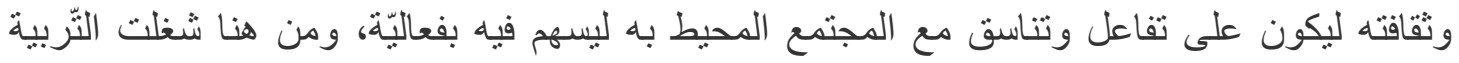
الكثير من الباحثين و الدّارسين على مر العصور ، وكان لها قدرٌ لا يُستهان به من الدر اسة و التحليل. التربية لغةً: التربية اسم مشتق من الربّ. الربّ: يطلق في اللغة على المالك والسيد والمُدِّبر والمُربيّ

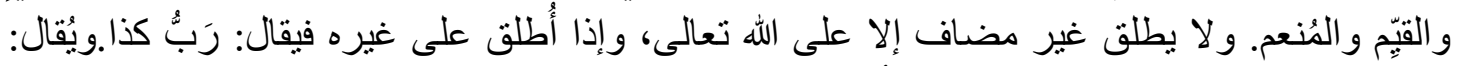

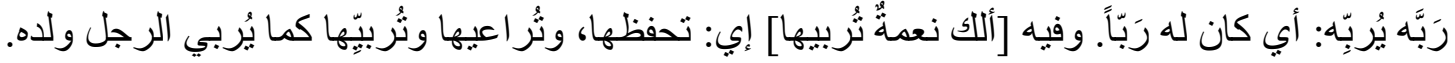

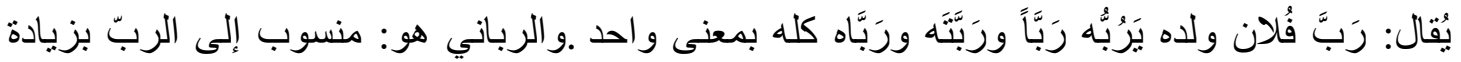

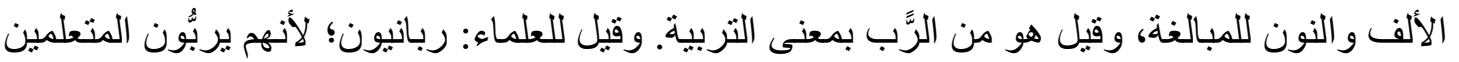

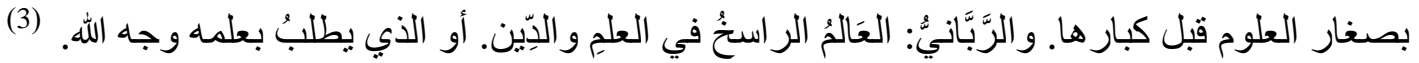

وقال ابن منظور في لسان العرب: التربية مشتقة من الفعل : ( ربا ) ، وتأتي على عدة معان ، منها:

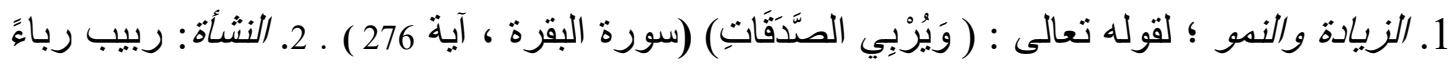

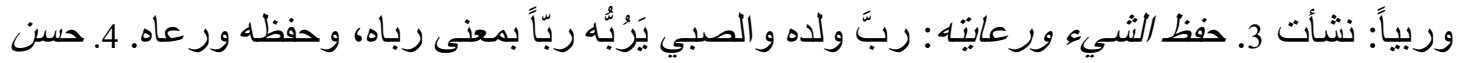

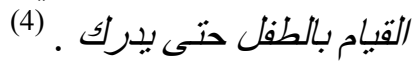

واستعملت كلمة التربية في القرآن الكريم بمعان شتى, منها:

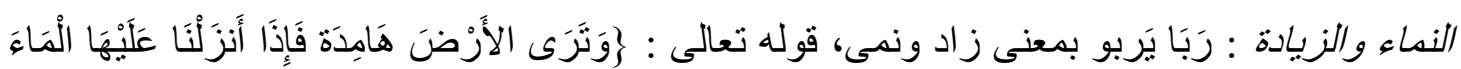

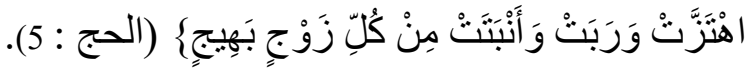

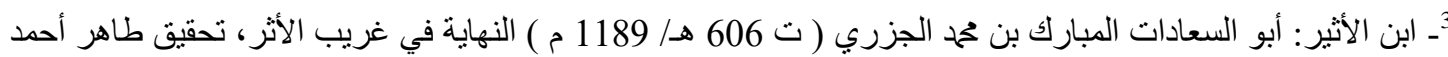

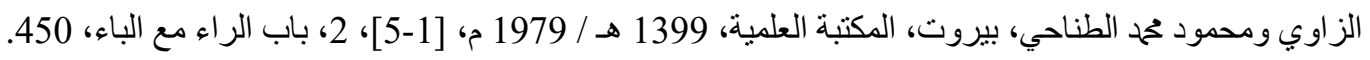

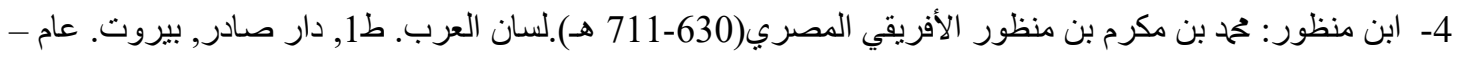

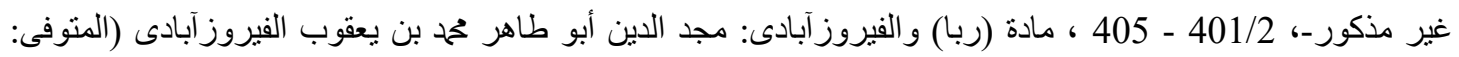

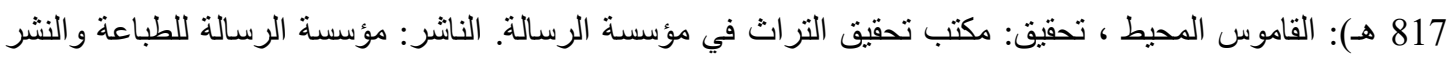

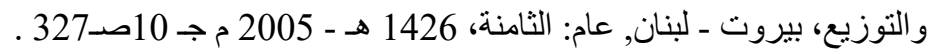




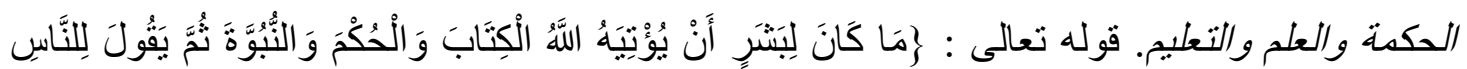

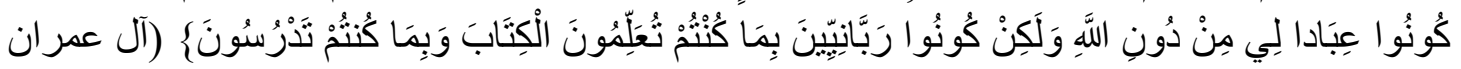

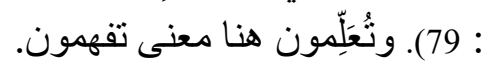

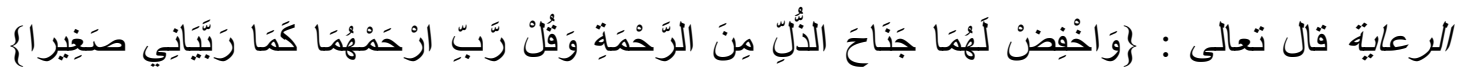
(الإسراء : (24). وتستعمل كلمة التربية بمعنى التهذيب و علو المنزلة، وقد ذكر ذللك الزمخشريُّ، فقال: " ومن المجاز :

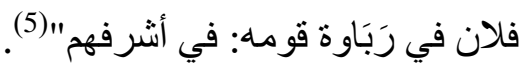
التربية اصطلاحاً: "يختلف تعريف التربية اصطلاحاً باختلاف المنطلقات الفلسفية، التي تسلكها الجماعات الإنسانية في تدريب أجيالها، وإرساء قِيمِها ومعتقداتها، وباختلاف الآر اء حول مفهوم العطية

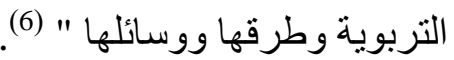

فقد ورد في تعريف التربية تعاريف متعددة منها :التربية: إنشاء الثيء حالاً فحالاً إلى حد التمام (7) التربية تعني: " تغذية الجسم وتربيته بما يحتاج إليه من مأكل ومشرب ليثّب قوياً معافى قادراً على الئ

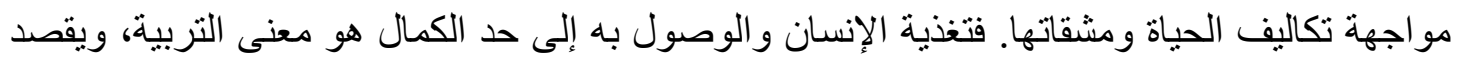

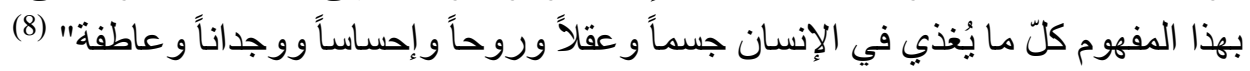

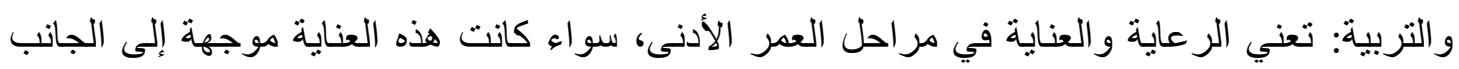

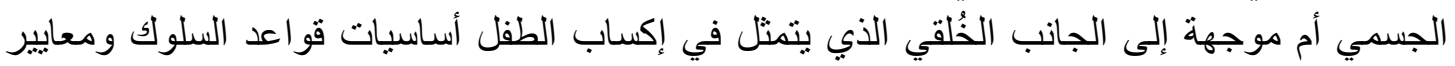
الجماعة التي ينتمي إليها"(9) - الجئ.

5ـ الزمخشري: محمود بن عمر جار الله ( ت 583 هـ/ 1134م ) أساس البلاغة، القاهرة، دار الكتب، ط1، 1341هـ/

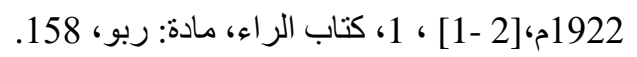

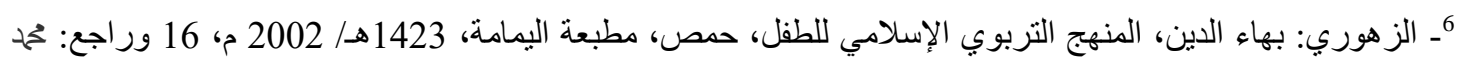

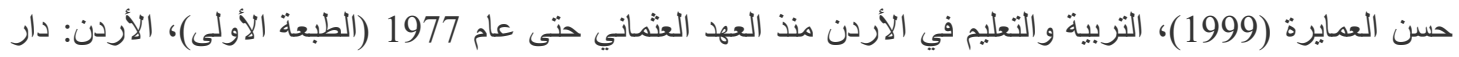

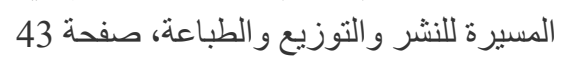

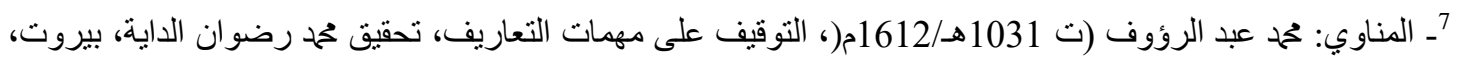

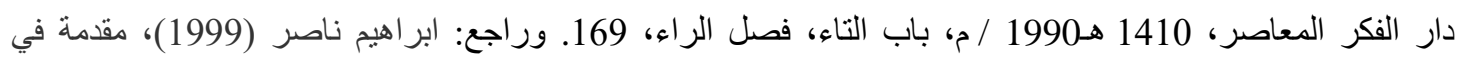

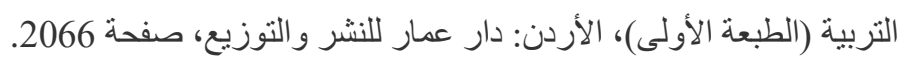

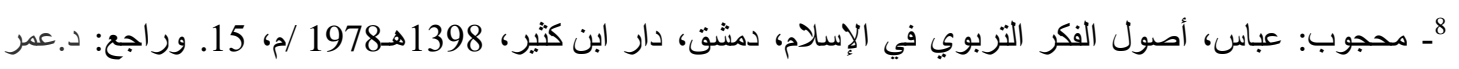

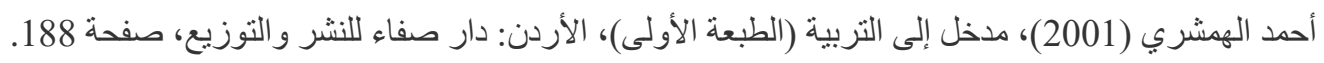

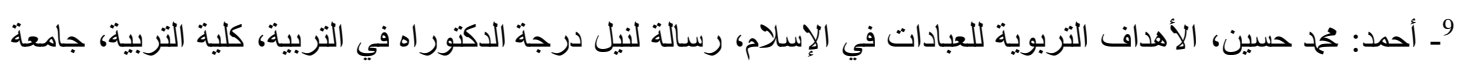
طنطا، قسم أول التربية، غير منشورة، 14. 


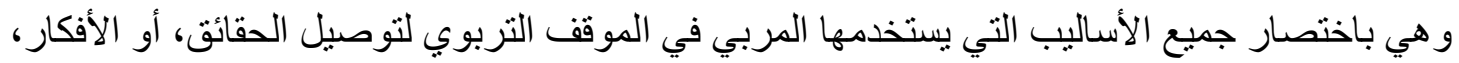

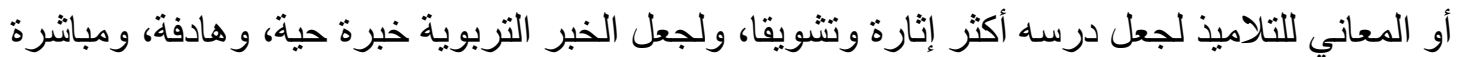
في نفس الوقت.

ومن خلال إطلاع محدود على بعض كتب السنة المطهرة وجدنا أن الرسول فئس قد استخدم وسائل

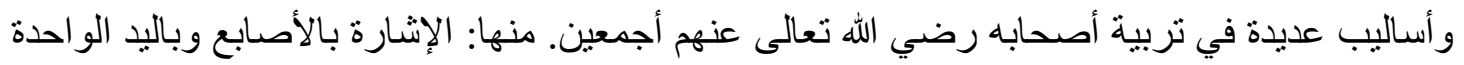

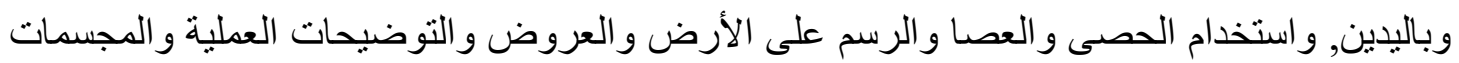
و الدمي و استخدام الأشياء الحقيقية و غير ها.

أولاً: الإشارة بالأصابع

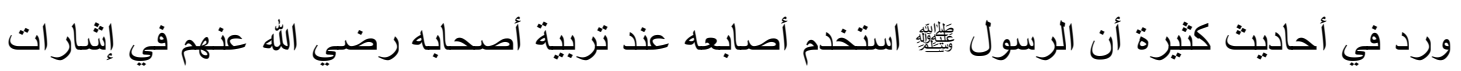

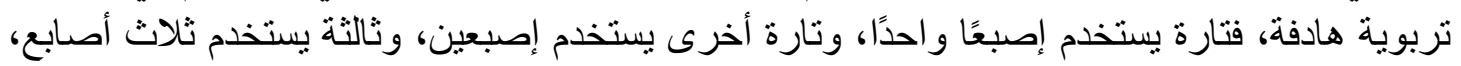

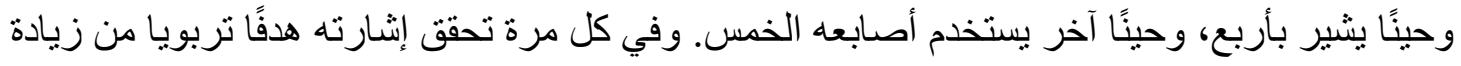

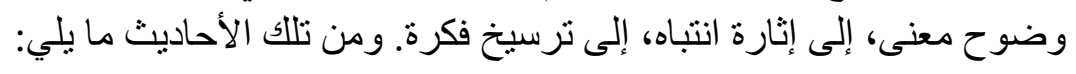

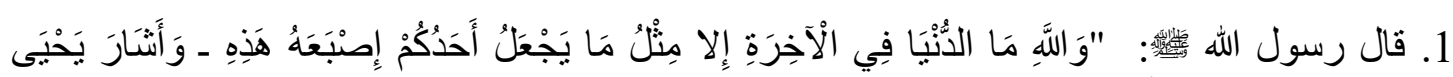

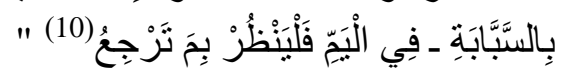

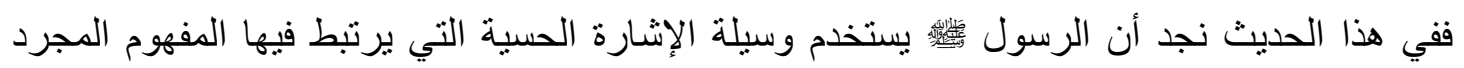

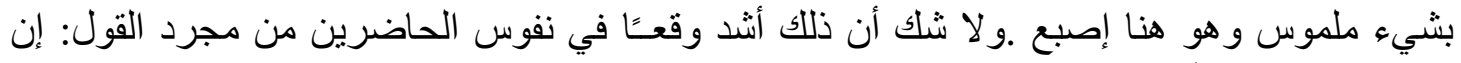

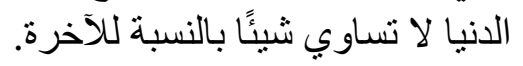

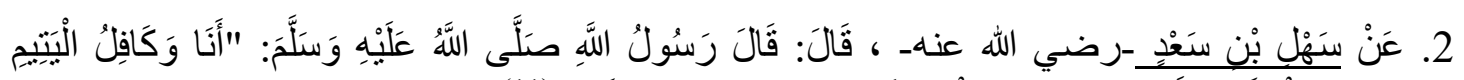

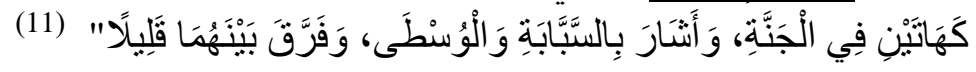
حيث أن الإشارة بالسبابة والوسطى والتفريج بينهما قليلاً تحدد المفهوم المقصود شرحه بأبلغ مما تفيده عبارة تقريرية: كافل اليتيم يكون قريبا من النبي صلي الله الهي عليه وآله وسلم في الجنة.

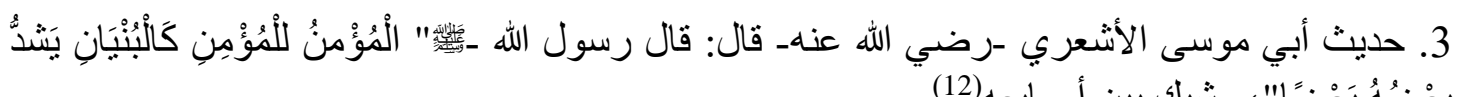

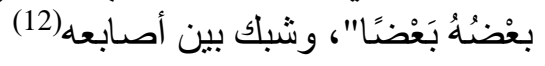

10 ـ صحيح مسلم , كتاب الجنة وصفة نعيمها وأهلها, باب فناء الدنيا وبيان الحشر يوم القبامة, رقم الحديث 2858. ـ ـويحيى أحد الراوة، و اليم هو البحر.

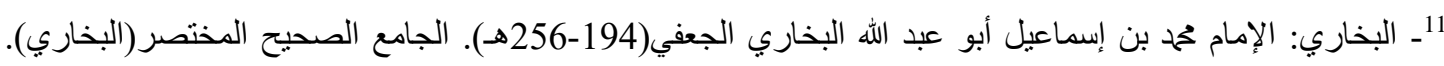

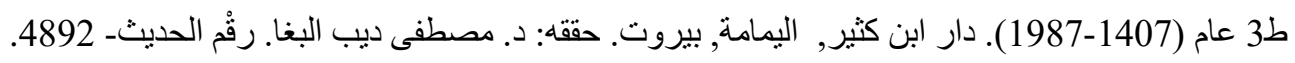
12 ـ أخرجه البخاري، كتاب المظالم والغصب، باب نصر المظلوم، (3/ (129) برقم: (2446)، ومسلم، كتاب البر و الصلة

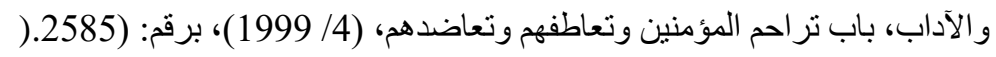


ثنانياً: الإشارة باليد

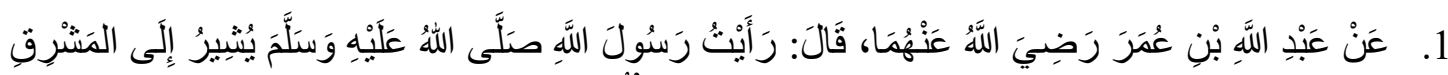

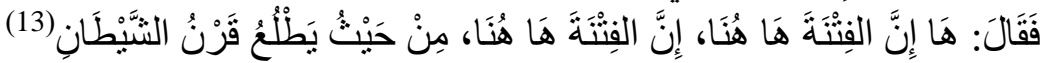

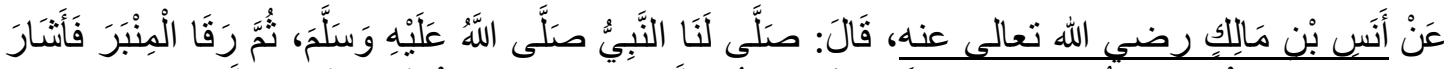

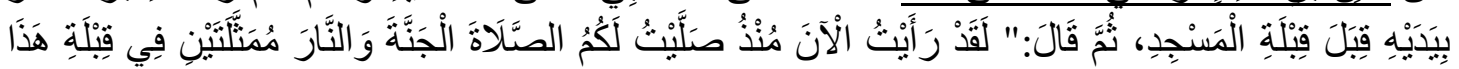

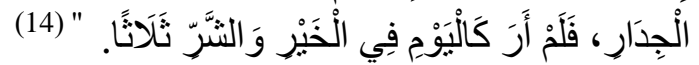

ثالثا: الإشـارة الى السمع والبصر

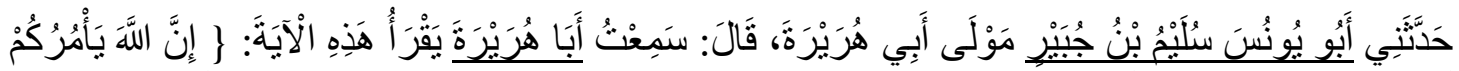

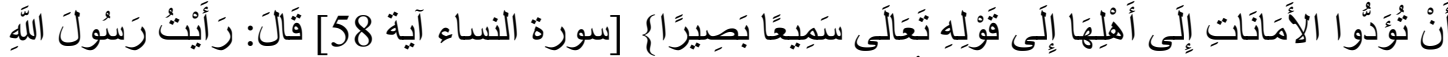

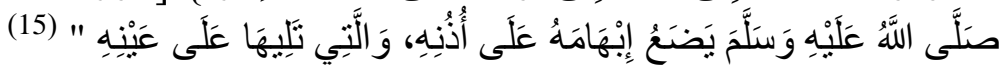

\section{رابعا: الإشارة إلى الوجه والكفين}

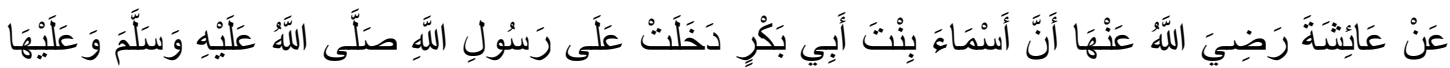

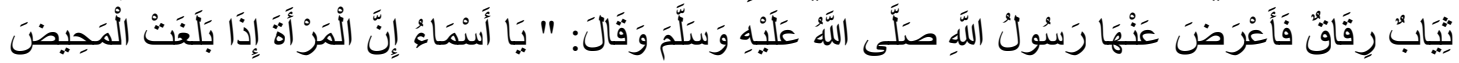

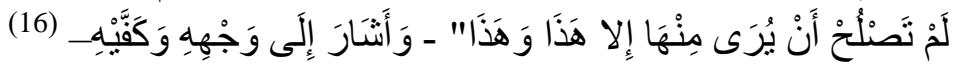

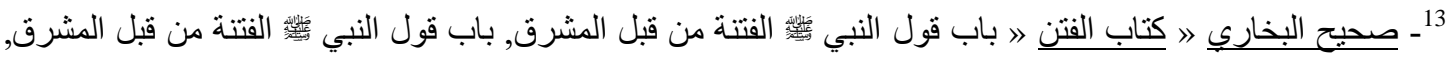

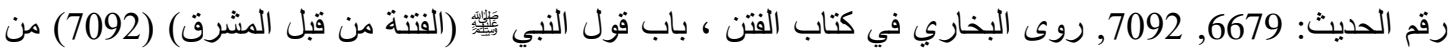

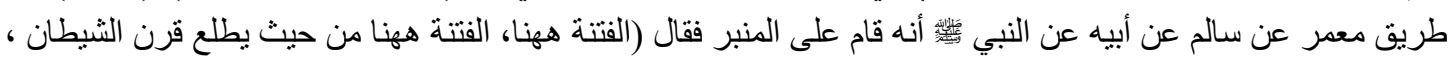

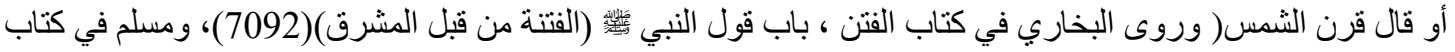

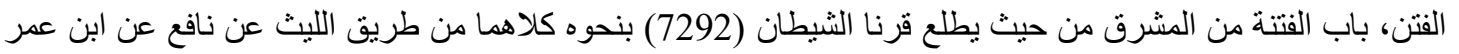

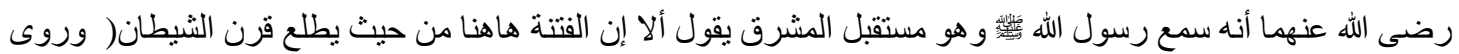

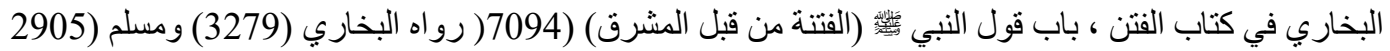

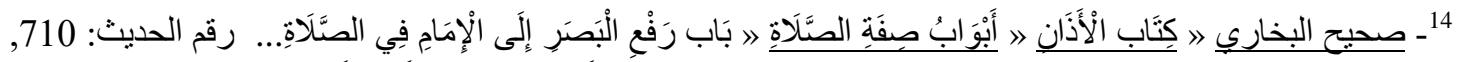

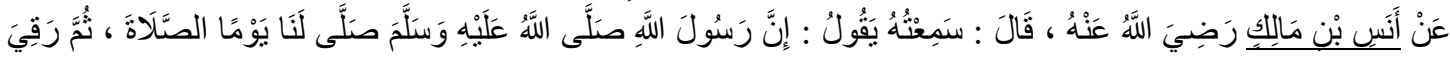

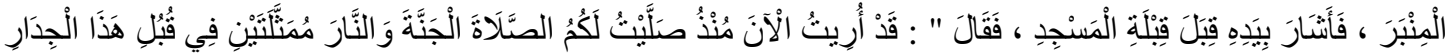

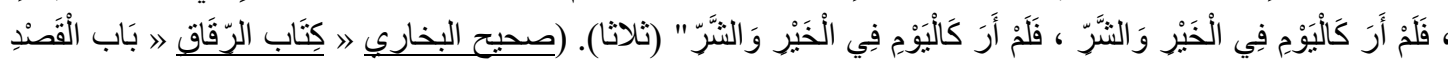

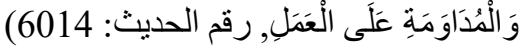

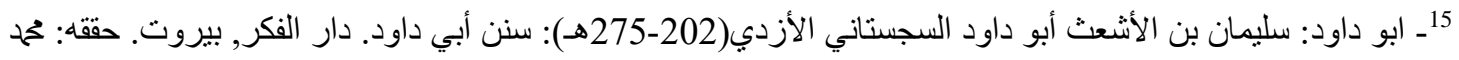

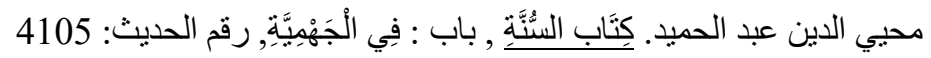

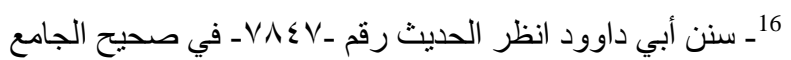




\section{خامسا: الإشارة إلى الأنف}

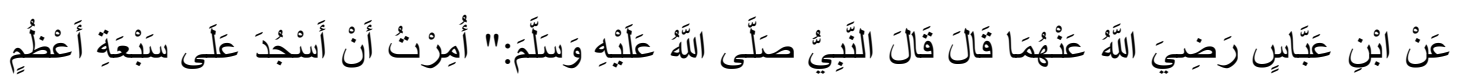

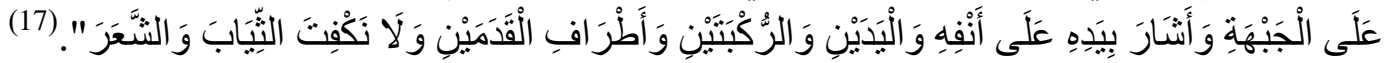

\section{سادسا: الإشارة إلى الفم}

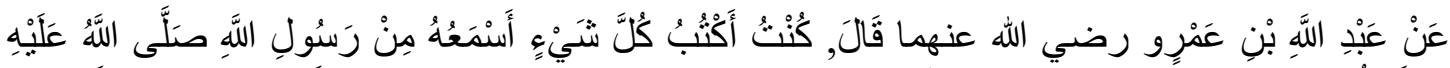

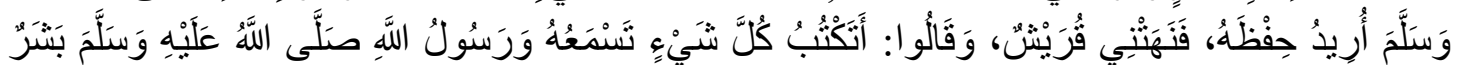

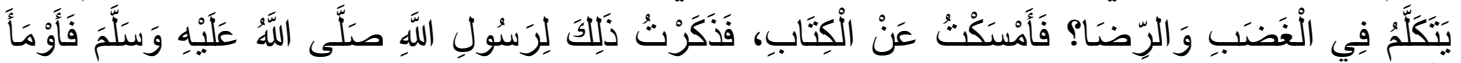

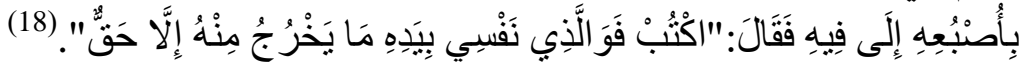

$$
\text { سابعا: الإشارة إلى الصدر }
$$

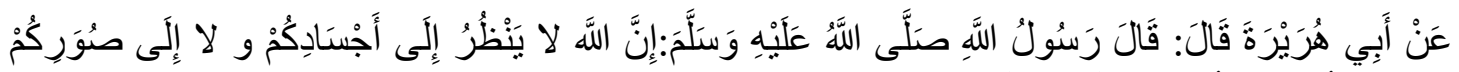

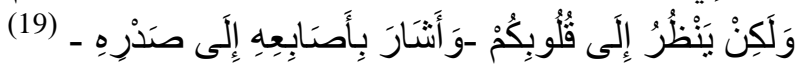

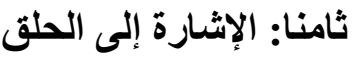

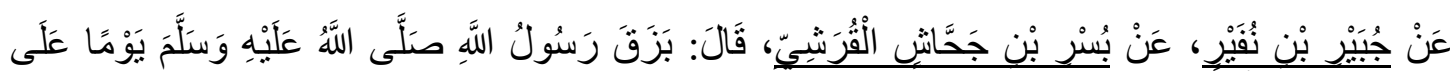

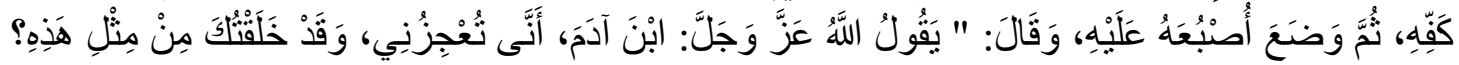

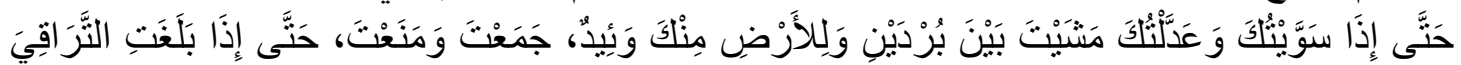

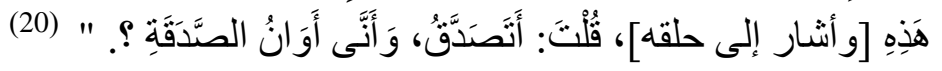

$$
\begin{aligned}
& \text { 17 ـ البخاري, كتاب الآذان,_رقم الحديث: } 816 \text { أخرجه : مسلم ـ كتاب الصلاة ، باب أعضاء السجود و النهي عن كف الثعر } \\
& \text { و الثوب و عقص الرأس في الصلاة ـ رقم (490. }
\end{aligned}
$$

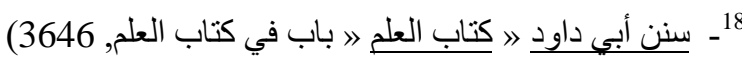

$$
\begin{aligned}
& \text { 19ـ أخرجه مسلم، كتاب البر والصلة والآداب، باب تحريم ظلم المسلم، وخذله، واحتقاره ودمه، وعرضه، وماله } \\
& \text { (2564) (1986/4)، رقم: (25) }
\end{aligned}
$$


تاسعا: الإشارة إلى اللسان

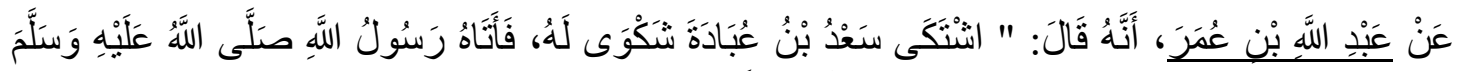

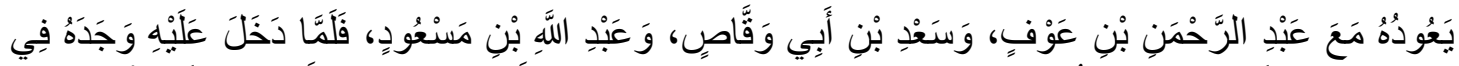

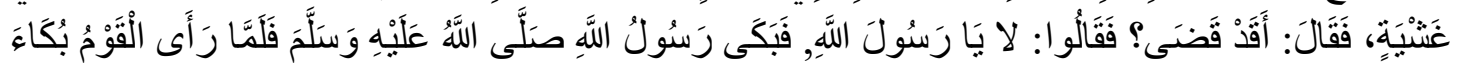

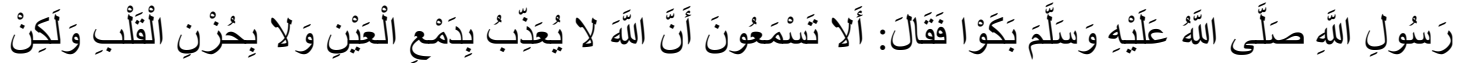

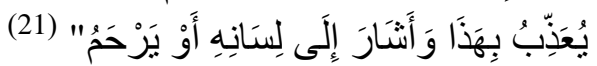

عاشرا: استخدام الحصى

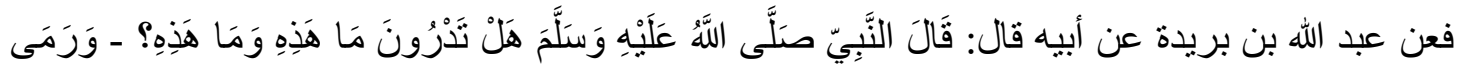

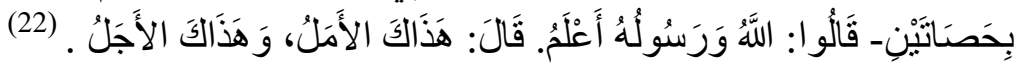

حادي عشر: استخدام العصا

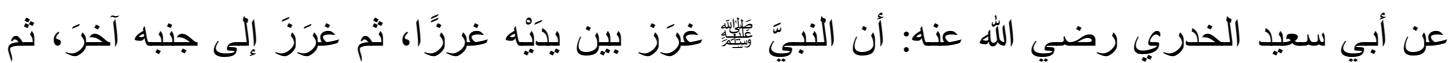

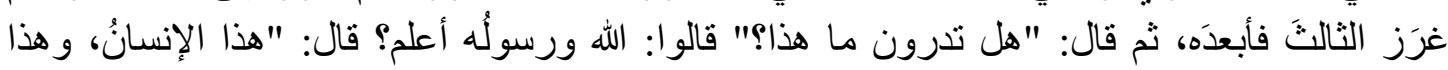

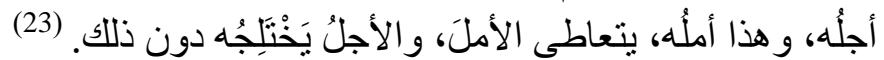

ثاني عشر: الرسم على الأرض

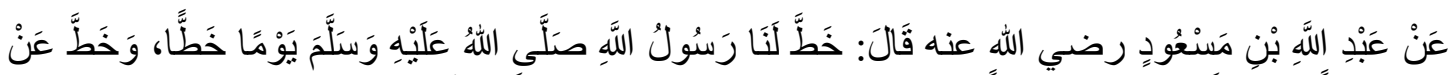

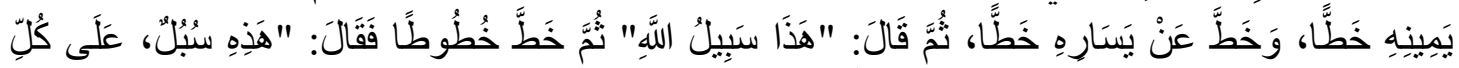

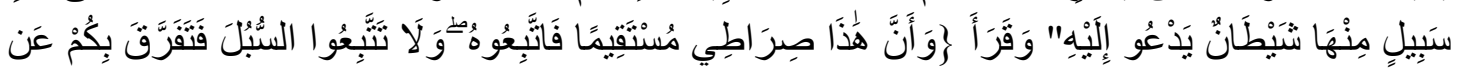

21 - صحيح البخاري » كتاب الجنائز 》 باب البكاء عند المريض, باب البكاء عند المريض 1242)

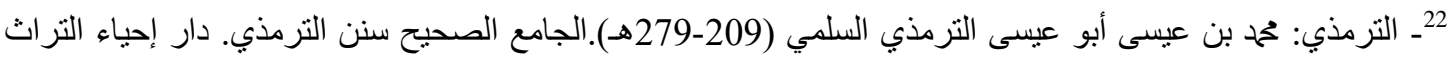

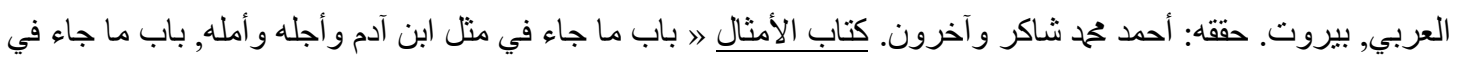

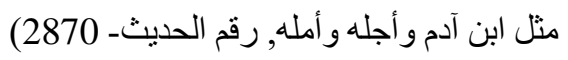

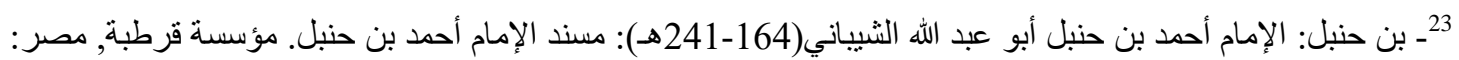

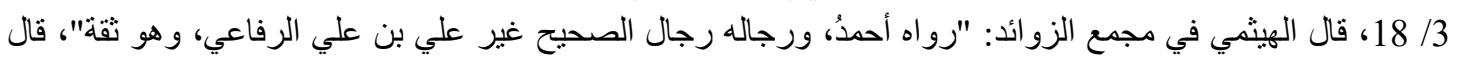

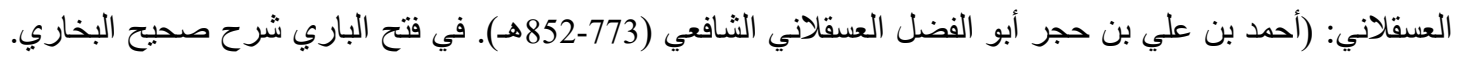

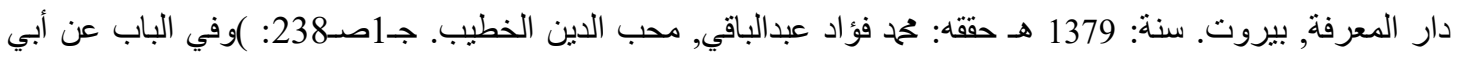

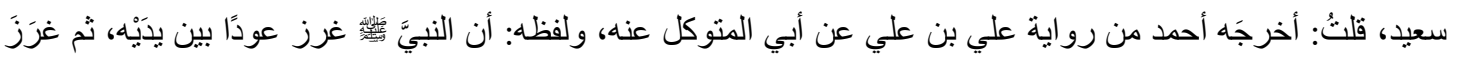

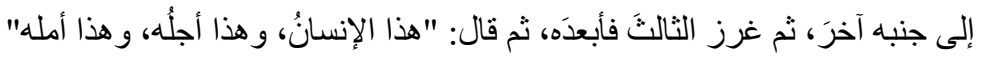




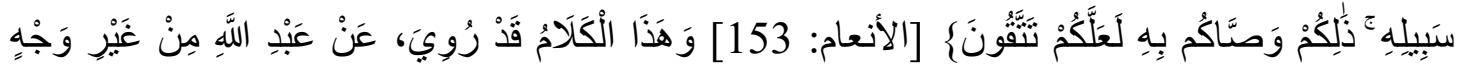

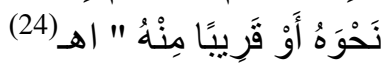

\section{ثالث عشر: العروض والتوضيحات العملية}

هناك بعد الأعمال و المهار ات الحركي التي تحتاج إلى تدريب عملي عليها لإتقانها على الوجه المطلوب, ولا يكفي فيها الشرح النظري. من أهم هذه التوضيحات:

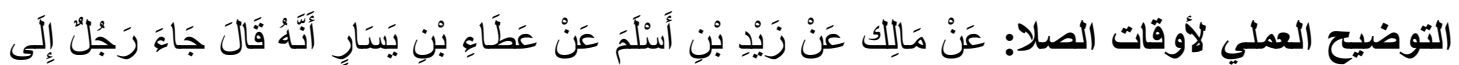

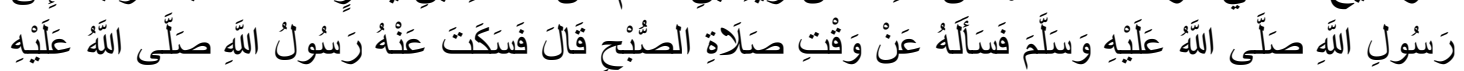

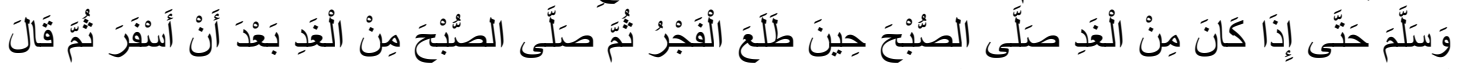

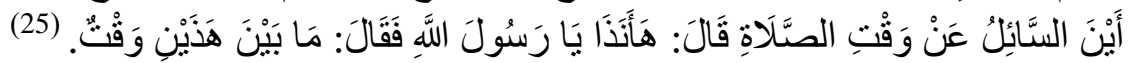

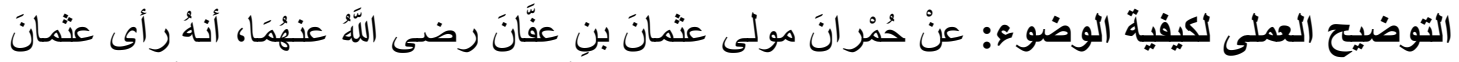

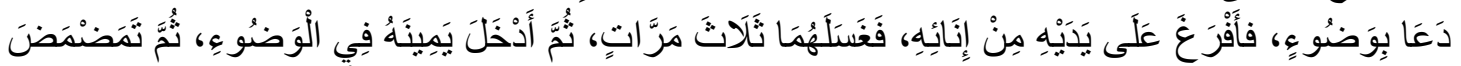

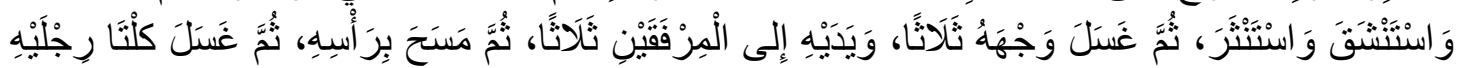

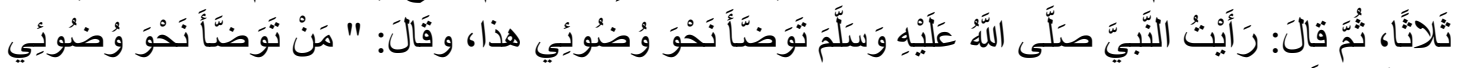

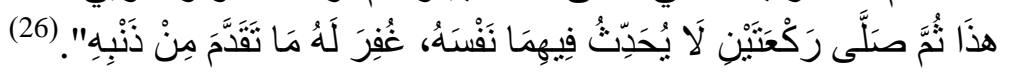

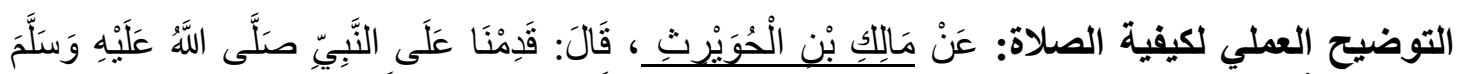

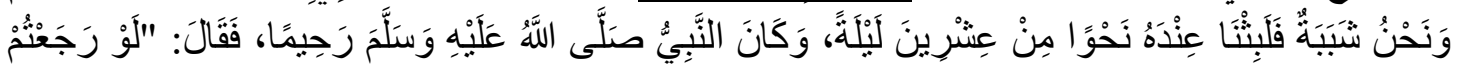

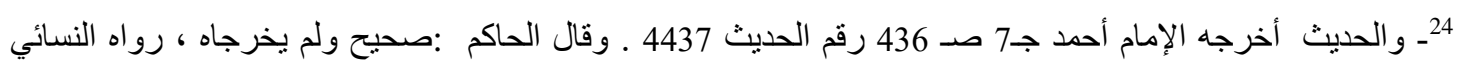

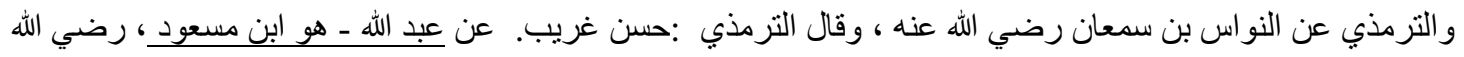

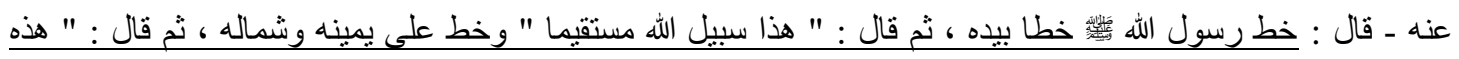

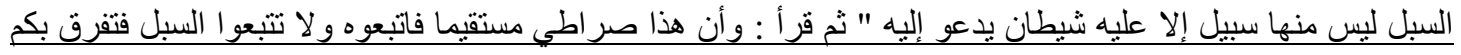

عن سبيله.

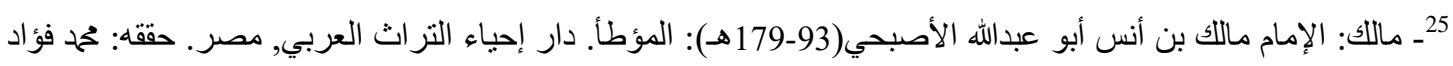
عبد الباقي. وقوت الصلاة 》 باب وقوت الصلاة والنسائي: الإمام أحمد بن شعيب أبو عبد الرحمن النسائي (215-303هـ).

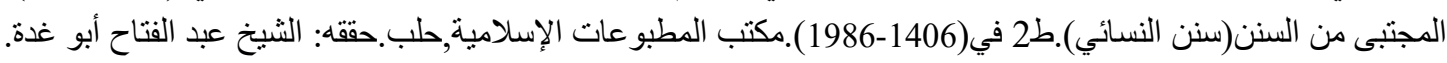
وبن عبد البر: ابو عمر يوسف بن عبد الله بن عبد البر النمري (368-463هـ):التمهيد لما في الموطأ من المعاني و الأسانيد.

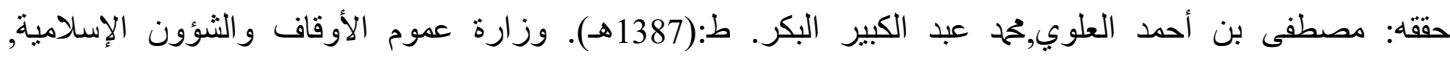

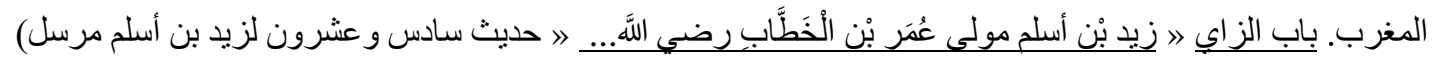

26 ـحيح مسلم 》 كتاب الطهارة 》 باب صفة الوضوء وكماله, 331 باب صفة الوضوء وكماله رقم الحديث: 226) 


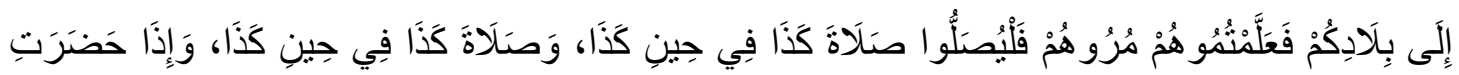

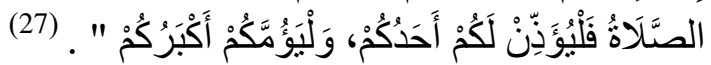

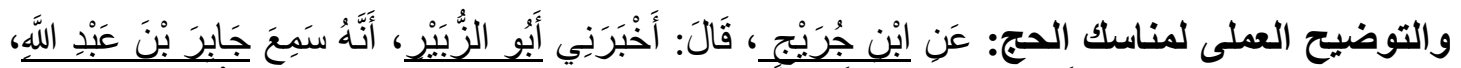

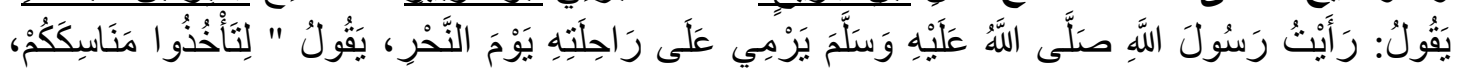

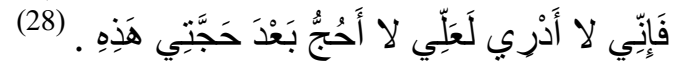

رابع عشر: استخذام الأشياء الحقيقية

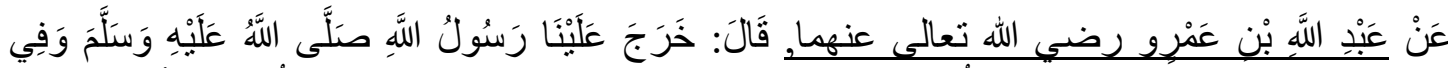

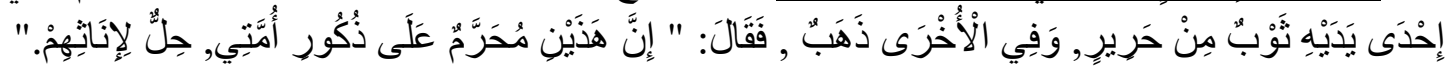

هذه هي بعض الأساليب التي استخدمها رسول الله

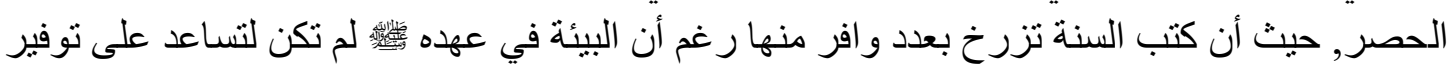
الكثير من أساليب التربية.

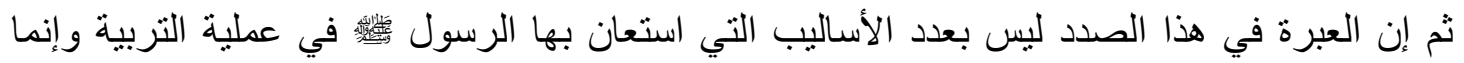

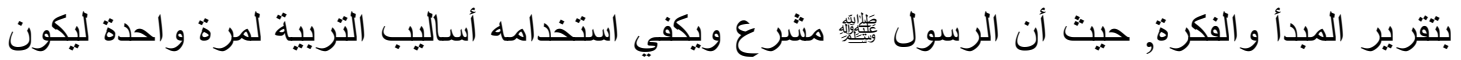
في ذلك أسوة و هليا للمربين و المعلمين في كل العبدول العصور .

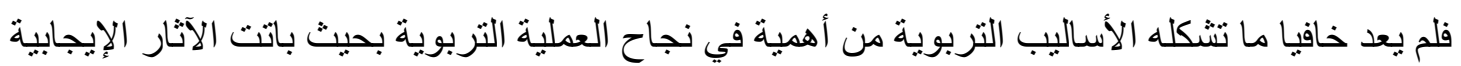
لاستخدام تلك الأساليب في التدريس من الدسلمات التربوية التي بر هنت على التى جدوالها التها الدراسات و أثنتها

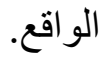

الخاتمة

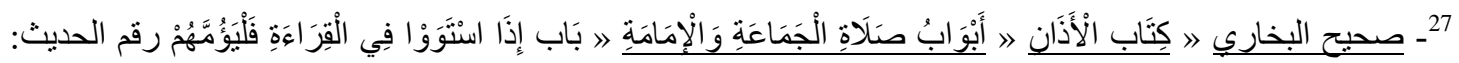
647 و رقم الحديث- 653. صحيح مسلم 465/1-466, رقم الحديث-674)

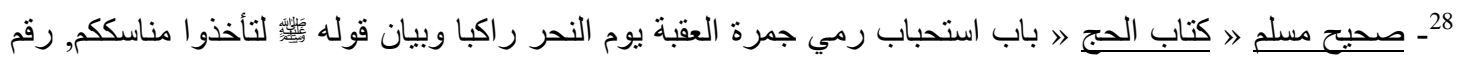

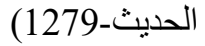
2- ــن ابن ماجه 》 كتاب اللباس 》 باب لبس الحرير و الذهب للنساء, رقم الحديث-3579) 


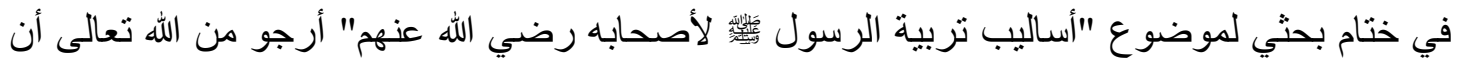

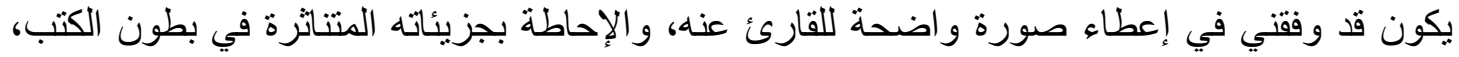

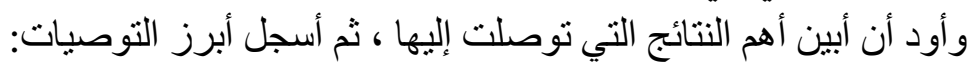

النتائج

من خلال هذه الدر اسة المتو اضعة وصلنا إلى بعض النتائج التى كنا ننتدها من الدر اسة, منها ما يلى:

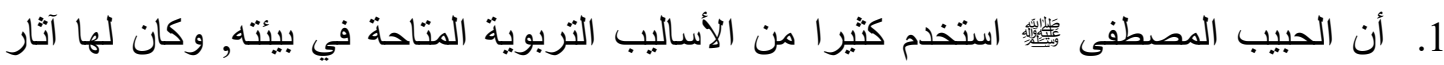

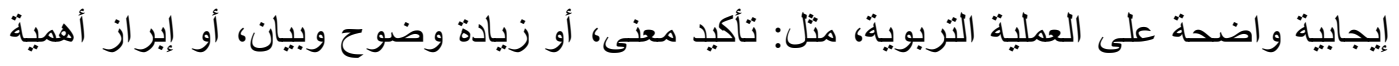

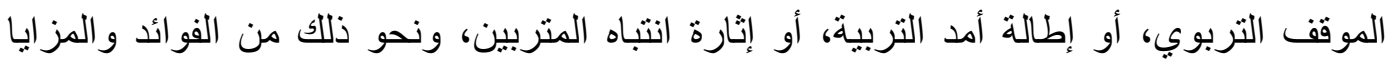
التربوية وتركت عظيم الأثر في نفوس الصحابة رضو التران الله تعالى عليهم أجمعين.

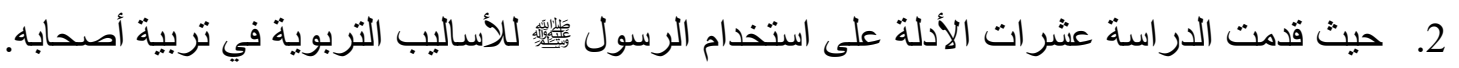

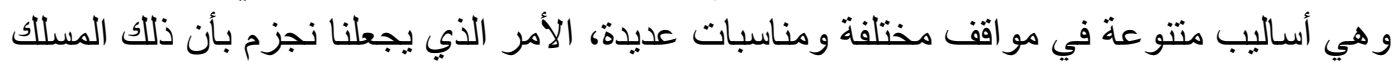

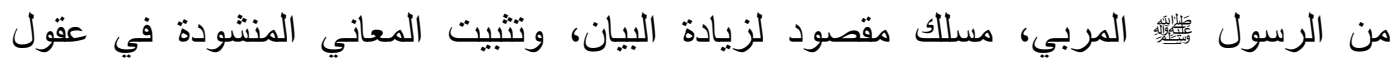
الحاضرين.

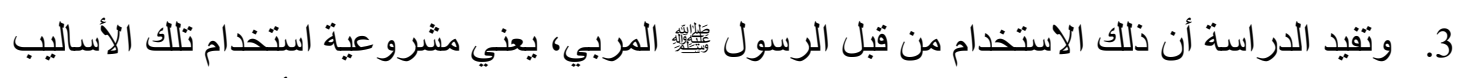

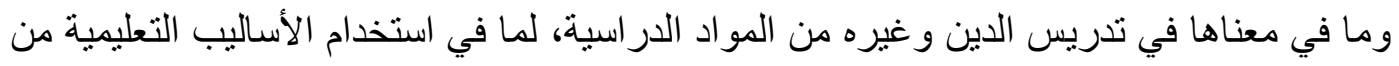

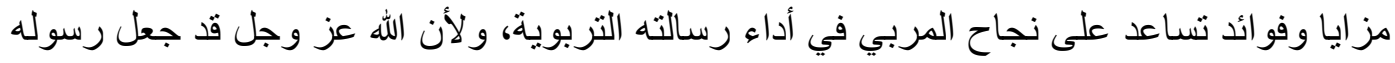

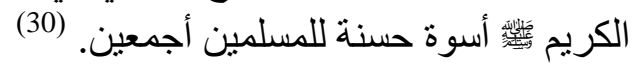

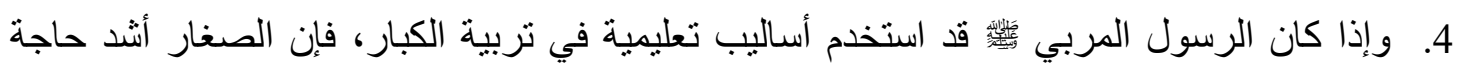

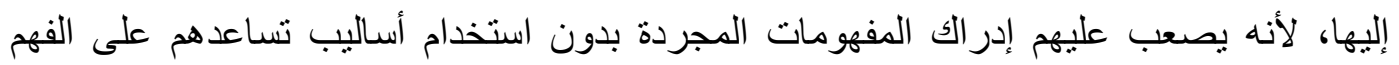
و الإدراك.

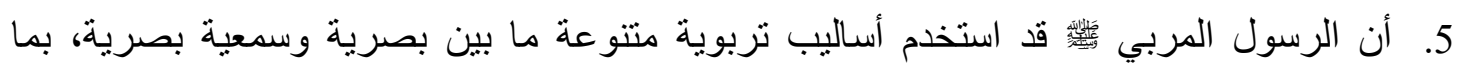

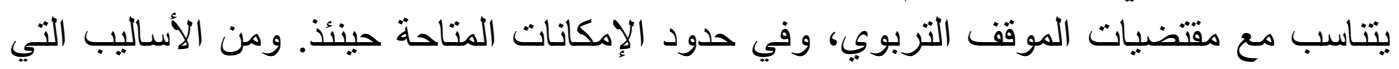

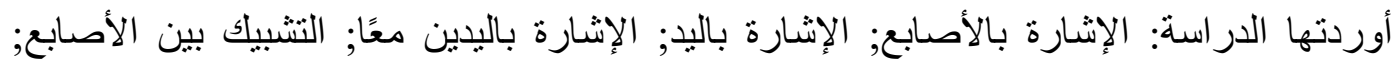

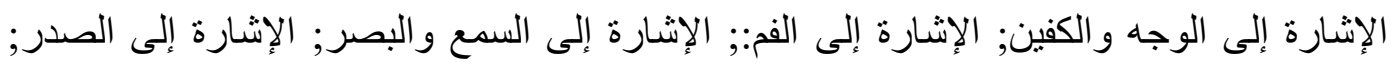

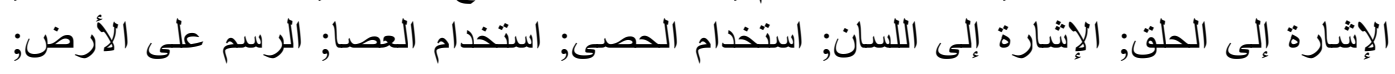
العروض أو التوضيحات العملية, واستخدام الأشياء الحقيقية.

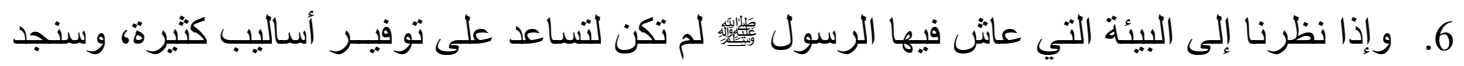

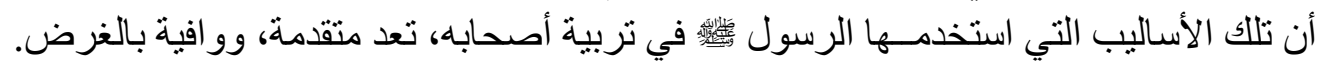

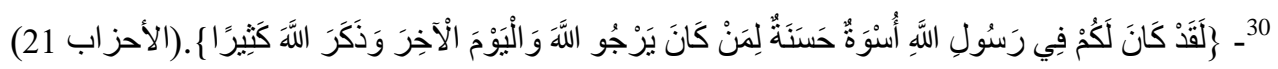


7. وأن هذه الدراسة، ربما اعتبرت إسهامًا متو اضعًا في الجهود الرامية إلى التأصيل الإسلامي للعلوم النفسية والتربوية. حيث إنه لا توجد - حسب علم البراحث ـدئ ـدراسة مستقلة تبحث في الأساليب

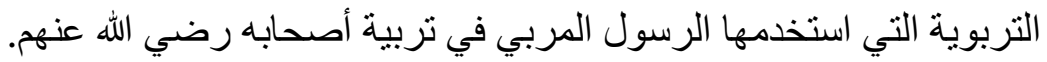

\section{المقترحات والتوصيات}

من خلال النتائج التي توصلت إليها أسفرت عنها هذه الدراسة، يمكن إير اد بعض التوصيات و المقترحات التي نرجو أن تكون نافعة.

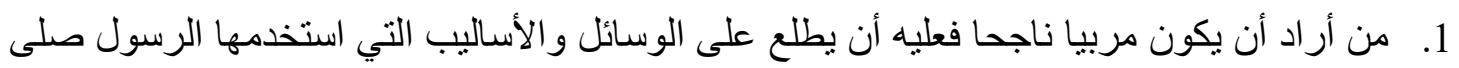

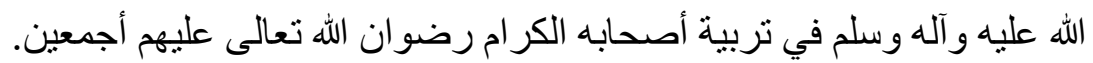

2. ولنجاح هذه المهمة أن تقام ورشة أعمال لتدريب المعلمين المربين ولإطلاعهم على البحوث

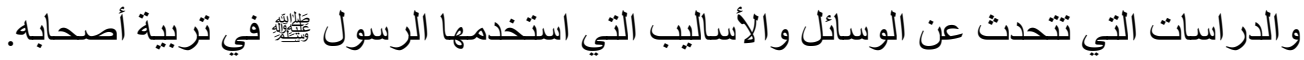

3. وأن تقام ندوات ومحاضرات وحوار ومناقثات حول تطيق هذا المنهج الناجح في عملية التربية و التعليم و التدريس.

4. أن تتضمن برامج إعداد وتدريب معلمي التربية الإسلامية مقررات عن الأساليب التربوية من

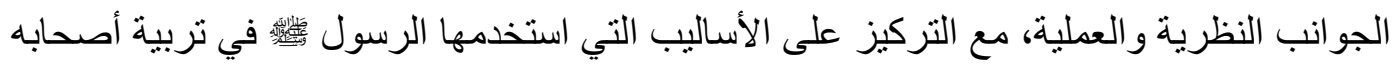

$$
\text { رضي الله عنهم. }
$$

5. أن يتم التأكيد في مناهج التربية الإسلامية على أهمية استخدام الأساليب التربوية، واعتبار ها جزءًا أساسيًا من المنهج ومن العملية التربوية برمنها لا يسع المعلية المعلم المربي الاستغناء عنها. 6. وأن تتضمن مناهج التربية الإسلامية وكتبها الدراسية عددًا من الأساليب التربوية اللازمة لتدريس تللك المناهج. وصلى الله على سيدنا محمد و على آله وصحبه وسلم.

\section{المراجع والمصادر

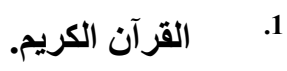

2. البخاري:الإمام محمد بن إسماعيل أبو عبدالله البخاري الجعفي(194-256هـ). الجامع الصحيح المختصر (البخاري). ط3 عام (1407-1987). دار ابن كثير, اليمامة, بيروت. حقفه: د. مصطفى ديب لهن

مسلم: الإمام مسلم بن الحجاج أبو الحسين القثيري النيسابوري(206-261هـ): صحيح مسلم. دار إحياء .3 التراث العربي, بيروت. حققه: محمد فؤاد عبد البام الباقي. 
4. ابو داود: سليمان بن الأشعث أبو داود السجتاني الأزدي(202-275هـ): سنن أبي داود. دار الفكر,

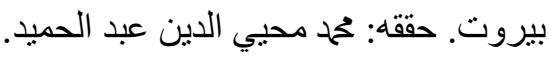
الترمذي: محمد بن عيسى أبو عيسى الترمذي السلمي (209-279هـ): الجامع الصحيح سنن الترمذي. دار

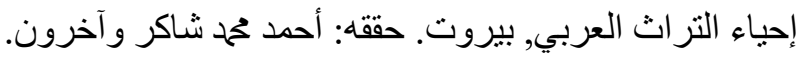
النسائي: الإمام أحمد بن شعيب أبو عبد الرحمن النسائي (215-303هـ). المجتبى من السنن(سنن النسائي).ط2 في(1406-1986).مكتبة المطبو عات الإسلامية, حلب.حققه: الثيخ عبد الفتاح أبو غدة. ابن ماجه: ححمد بن يزيد أبو عبد الله القزويني(207-275هـ): سنن ابن ماجه. حققه: محمد فؤاد عبد الباقي. دار

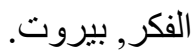
مالكك: الإمام مالك بن أنس أبو عبدالله الأصبحي(93-179هـ): المؤطأ. دار إحياء التراث العربي, مصر.

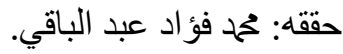

بن حنبل: الإمام أحمد بن حنبل أبو عبد الله الثيباني(164-241هـ): مسند الإمام أحمد بن حنبل. مؤسسة قرطبة, مصر.

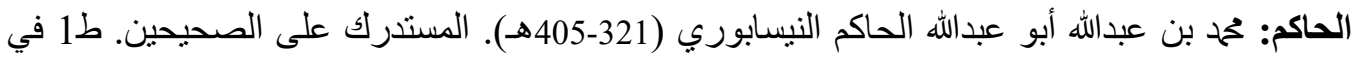
سنة: 1411 - 1990. دار الكتب العلية, بيروت. حققه: مصطفى عبد القادر عطا. العقلاني: أحمد بن علي بن حجر أبو الفضل العسقلاني الثافعي (773-852هـ): فتح الباري شرح

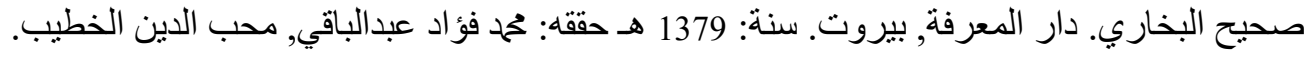
بن عبد البر: ابو عمر يوسف بن عبد الله بن عبد البر النمري (368-463هـ):التمهيد لما في الموطأ من هن

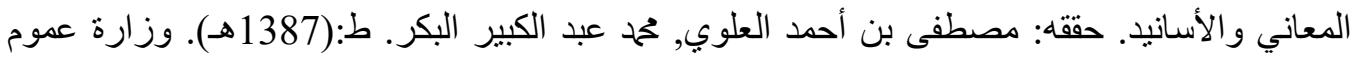

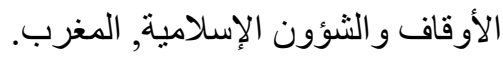

حسين حمدي الطوبجي: وسائل الاتصال والتكنولوجيا في التعليم، (كويت: دار القلم ، 1987م) ابن الأثير: أبو السعادات المبارك بن محم الجزري ( ت 606 هـ/ 1189م ) النهاية في غريب الأثر، تحقيق

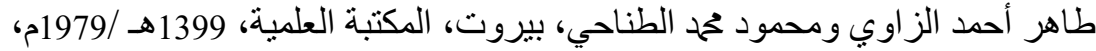
ابن منظور : لسان العرب. ط1, دار صادر, بيروت. عام - غير مذكور -

الفيروزآبادى: مجد الدين أبو طاهر محمد بن يعقوب الفيروزآبادى (المتوفى: 817هـ): القاموس المحيط ،

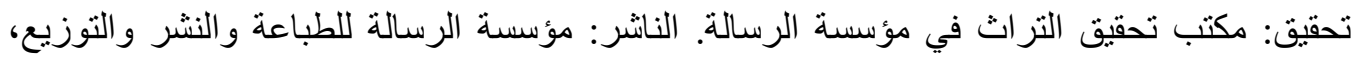

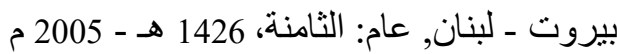

$$
\text { ابن معين: يحيى بن معين أبو زكريا (158-233هـ)... }
$$

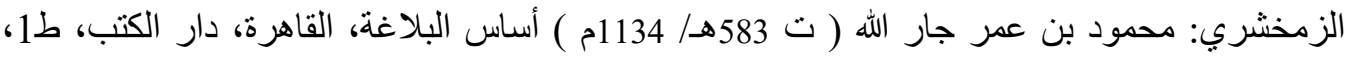




$$
\begin{aligned}
& \text { SAYED MOHAMMAD JALAL UDDIN AL-AZHARI أساليب تربية الرسول } \\
& \text { 20. العمايرة: ححمد حسن العمايرة (توفي-1999)، التربية والتعليم في الأردن منذ العهد العثماني حتى عام }
\end{aligned}
$$

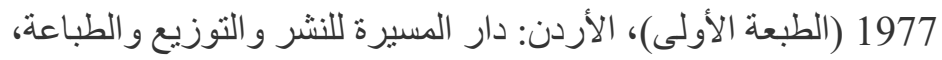

$$
\begin{aligned}
& \text { 21. المناوي: مححد عبد الرؤوف (ت 1031هـ/1612م(، التوقيف على مهمات التعاريف، تحقيق تحمد رضوان }
\end{aligned}
$$

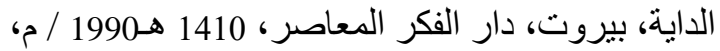

$$
\begin{aligned}
& \text { 22. } \\
& \text { 23. محجوب: عباس، أصول الفكر التربوي في الإسلام، دمشق، دار ابن كثير، 1398هـ1978م،. } \\
& \text { 24. الهمشري: د.عمر أحمد الهمشري ، مدخل إلى التربية (الطبعة الأولى2001 م ) ، الأردن: دار صفاء } \\
& \text { للنشر و التوزيع. } \\
& \text { 25. أحمد: محمد حسين، الأهداف التربوية للعبادات في الإسلام، رسالة لنيل درجة الدكتور اه في التربية، كلية } \\
& \text { التربية، جامعة طنطا، قسم أول التربية، غير منشورة التهن }
\end{aligned}
$$

\section{Endnotes}

1. Al-Qur'an.

2. Bukhari: Imam Muhammad bin Ismail Abu Abdullah al-Bukhari al-Ju'fi (194-256). Al Jame Al Sahih Al Mukhtasar (Bukhari). $3^{\text {rd }}$ Edition (1407-1987). Dar Ibn Katheer, Al Yamama, Beirut. Tahqiq by: Dr. Mostafa Deeb El Baga.

3. Muslim: Imam Muslim bin Hajjaj Abu al-Husain al-Qushairi al-Nisaburi (206-261): Saheeh Muslim. Dar revival of Arab heritage, Beirut. Tahqiq by: Mohamed Fouad Abdel Baqi.

4. Abu Dawood: Sulaiman ibn al-Ash'ath Abu Dawood al-Sijistani al-Azdi (202-275): Sunan Abu Dawood. Dar Al Fikr, Beirut. Tahqiq by: Mohamed Mohiuddin Abdel Hamid.

5. Tirmidhi: Muhammad bin Isa Abu Issa Tirmidhi Al Sulami (209-279): Al Jame Al Sahih (Sunan Tirmidhi). Dar revival of Arab heritage, Beirut. Tahqiq by: Ahmed Mohammed Shaker and others.

6. Al Nasayee: Imam Ahmad bin Shu'aib Abu Abd al-Rahman Al Nasayee (215-303 e). Mujtaba of Sunan (Sunan Al Nasayee). $2^{\text {nd }}$ Edition (1406-1986). Library of Islamic publications, Aleppo. Tahqiq: Sheikh Abdul Fattah Abu Ghiddah.

7. Ibn Majah: Muhammad ibn Yazid Abu Abdullah al-Qazwini (207-275): Sunan Ibn Majah. Tahqiq by: Mohamed Fouad Abdel Baqi. Dar Al Fikr, Beirut.

8. Malik: Imam Malik bin Anas Abu Abdullah Al-Asbahi (93-179): Moutta. Arab Heritage Revival House, Egypt. Tahqiq by: Mohamed Fouad Abdel Baqi. 
9. Ibn Hanbal: Imam Ahmad bin Hanbal Abu Abdullah al-Shaibani (164-241): Musnad Imam Ahmad bin Hanbal. Qortoba Foundation, Egypt.

10. Al Hakem: Muhammad bin Abdullah Abu Abdullah Al Hakem al-Naisabouri (321405). Al Mustadrak Alal Sahihain. $1^{\text {st }}$ edition in the year: 1411 - 1990. Scientific Book House, Beirut. Tahqiq by: Mustafa Abdel kader Ata.

11. Al-Asqalani: Ahmad ibn Ali ibn Hajar Abu al-Fadl al-Asqalani al-Shafei' (773-852): Fath al-Bari Sharh saheeh al-Bukhaari. Dar Al Ma'refa, Beirut. Year: 1379 AH Tahqiq by: Mohamed Fouad Abdel Baki, Muhib Al Din Al-Khatib.

12. Ibn Abd al-Barr: Abu Omar Yusuf bin Abdullah bin Abdul-Barr al-Nimari (368-463 AH): At Tamhid Lima Fi Al Muatta Min Al Ma'ni Wal Asaneed. Tahqiq by: Mustafa bin Ahmed Al-A'lawi, Mohammed Abdul Kabir al-Bakr. $1^{\text {st }}$ edition: (1387 ad). Ministry of the General Awqaf and Islamic Affairs, Morocco.

13. Hussein Hamdi Al-Tubji: Wasayel Al Ittisal Wa At Taknologia Fi At Ta,lim (Means of Communication and Technology in Education) (Kuwait: Dar Al-Qalam, 1987)

14. Ibn al-Atheer: Abu al-Saadat al-Mubarak bin Muhammad al-Jazri (d. 606 AH / 1189 AD) Al Nihaya Fi Gharib al-Atar, Tahir Ahmed al-Zawi and Mahmoud al-Tannahi, Beirut, The Scientific Library, 1399 AH / 1979,

15. Ibn Manzoor: Lisan Al Arab. $1^{\text {st }}$ editing, Dar Sa-der, Beirut. Year- not mentioned -

16. Al Firouzabadi: Majd al-Din Abu Tahir Mohammed bin Yaqoub Al-Fayrouzabadi, Al Qamus Al Muhit. Tahqiq: Al-Resala Foundation. Publisher: Al-Resala Foundation for Printing, Publishing and Distribution, Beirut - Lebanon, Year: 8, 1426H - 2005.

17. Ibn Mu'in: Yahya bin Moeen Abu Zakaria (158-233).

18. Al-Zamakhshari: Mahmoud bin Omar Jarallah (d. 583 AH / 1134 AD) Asas al-Balagha, Cairo, Dar al-Kutub, $1^{\text {st }}$ edition, 1341 AH / 1922 AD,

19. Al-Zahwari: Bahaa El-Din, Al Manhaj At tarbavi Al Islami Li At tifl (The Islamic Educational Curriculum for the Child), Hims, Al-Yamamah Press, 2002,

20. Al-Amayerah: Mohamed Hassan Al-Amayerah (died 1999), At tarbiah Wa At ta'lim Fi Al Urdun Munz Al A'hd Al Osmani Hatta A'M 1977 (Education in Jordan from the Ottoman period until 1977 (first edition), Jordan: Dar Al Masirah for Publishing, Distribution and Printing, 
21. Al Manawi: Muhammad Abdul Raouf (1031 AH / 1612 AD), At tawqif A'la Muhimmatit Ta'fif, Tahqiq: Muhammad Radwan Al-Daya, Beirut, Dar Al Fikr Al Mu'sir, 1410H / 1990.

22. Nasser: Ibrahim Nasser, Muqaddama Fi At tarbiah (Introduction to Tarbiah) first edition, 1999, Jordan: Dar Ammar Publishing and Distribution.

23. Mahjoub: Abbas, Usul Al Fikr At tarbavi Fi Al Islam Bacis of Educational Thought in Islam) Damascus, Dar Ibn Katheer, 1398 AH, 1978.

24. Al-Hamshari: Dr. Omar Ahmad Al-Humshari, Madkhal Ila At tarbiah (Introduction to Tarbiah) first edition 2001, Jordan: Dar Safa for Publishing and Distribution.

25. Ahmed: Muhammad Hussein, Al Ahdaf Al Tarbavia Li Al Ibadaat Fi Al Islam (Educational Objectives of the Cultures in Islam) Thesis for the Degree of Doctor of Education, Faculty of Education, Tanta University, Department of Education (unpublished). 